Canadian Science Publishing

Botany

Botanique

\title{
Pollination biology of Cleomella serrulata and Polanisia dodecandra in a protected natural prairie in Southern Alberta, Canada
}

\begin{tabular}{|r|l|}
\hline Journal: & Botany \\
\hline Manuscript ID & cjb-2015-0084.R2 \\
\hline Manuscript Type: & Article \\
\hline Complete List of Authors: & $\begin{array}{l}\text { Higuera-Díaz, Mónica; University of Alberta, Biological Sciences; } \\
\text { Manson, Jessamyn; University of Alberta, Biological Sciences } \\
\text { Hall, Jocelyn; University of Alberta, Biological Sciences }\end{array}$ \\
\hline Keyword: & $\begin{array}{l}\text { Cleomaceae, Cross-pollination, Generalist pollination system, Native plants, } \\
\text { Prairie }\end{array}$ \\
\hline \multicolumn{2}{|c}{} \\
\hline
\end{tabular}

\section{SCHOLARONE \\ Manuscripts}




\section{Pollination biology of Cleomella serrulata and Polanisia dodecandra in a protected natural prairie in Southern Alberta, Canada}

Mónica Higuera-Díaz

Jessamyn S. Manson

Jocelyn C. Hall

Department of Biological Sciences, CW 405 Biological Sciences Building, University of Alberta, Edmonton, AB T6G 2E9, Canada (e-mail: higuera@ualberta.ca)

Department of Biological Sciences, CW 405 Biological Sciences Building, University of Alberta, Edmonton, AB T6G 2E9, Canada (e-mail: jessamyn.manson@ualberta.ca)

Department of Biological Sciences, CW 405 Biological Sciences Building, University of Alberta, Edmonton, AB T6G 2E9, Canada (e-mail: jocelyn.hall@ualberta.ca)

Corresponding author: Mónica Higuera-Díaz. Department of Biological Sciences, CW 405 Biological Sciences Building, University of Alberta, Edmonton, AB T6G 2E9, Canada, phone 780 4920083, fax 7804929234 (e-mail: higuera@ualberta.ca) 


\section{ABSTRACT}

Flowering plants that attract a diverse range of pollinators represent a generalist pollination system. Studying these plants provides valuable information about accessibility of floral resources to pollinators, which is particularly important in areas where scarcity of flowers limits pollinator populations. Here we describe the flowering phenology, reproductive biology, and visitor community of Cleomella serrulata and Polanisia dodecandra, two native species with generalist pollination systems and limited distribution in Albertan prairies. Although their flowers are similar, they differ in traits such as petal colour, inflorescence size and nectar display. Both species were facultatively cross-pollinated and exhibited nocturnal anthesis but differed in nectar production patterns. Cleomella produced highest nectar volume in the morning and highest sugar concentration at noon; while, Polanisia produced highest nectar volume before noon but sugar concentrations were higher at sunset. We observed 150 insect taxa visiting the plants, with Hymenoptera and Diptera as the most frequent visitors for Cleomella and Polanisia respectively. We recorded the first nocturnal flower visitors for Cleomella and the first record of Synnervus plagiatus for Alberta. Both species present effective nectar and pollen resources for pollinators at the study sites and may be useful in the maintenance of native pollinators in at-risk prairie ecosystems.

\section{KEY WORDS:}

Cleomaceae, Cross-pollination, Generalist pollination system, Native plants, Pollination biology, Prairie 


\section{INTRODUCTION}

Animal-mediated pollination is a process of great biological importance for the reproduction of plants and is an essential provisioning ecosystem service in which pollinators increase seed set of crops and native plants (Klein et al. 2007; Proctor et al. 1996; Willmer 2011). The availability of floral resources is critical to the survival of pollinators, which in turn increases the chances of cross-pollination in plants (Free 1993). Native plants play a crucial role in contributing to the biodiversity of natural ecosystems and also provide food, forage resources and nesting sites for different populations of pollinators. Thus, maintaining sustainable native plant populations and their associated pollinator communities benefits wild and managed ecosystems (Garibaldi et al. 2014). Unfortunately, many native plants and their pollinators are facing threats including reduction and loss of habitat and the introduction of invasive species. This is particularly true of plants found in native prairies, which are one of the most threatened ecosystems in North America (Fuhlendorf et al. 2002; Samson and Knopf 1994; Sheffield et al. 2014).

In prairie ecosystems, native flowering forbs and shrubs provide diverse foraging resources for pollinators. Dominant native plant species in prairies are wind pollinated (Kevan 1999; Moldenke 1976), while shrub and forb species frequently exhibit open and non-specialized flowers that are visited by a broad spectrum of pollinators (Hegland and Totland 2005; Kevan 1999). This phenomenon is known as a generalist pollination system (Hegland and Totland 2005; Herrera 1996; Waser et al. 1996). Annual plant species tend to have generalized pollination systems because relying on specialist pollinators, which may experience annual fluctuations in abundance, is risky (Waser et al. 1996). Studying native prairie plants with generalized pollination systems provides valuable information about the availability of floral resources to pollinators in an ecosystem where the scarcity of flowers could limit pollinator populations. In Alberta, two rare 
native species of Cleomaceae persist in the southeast part of the province and exhibit flowers consistent with a generalist pollination system (Cane 2008a, b; Smith et al. 2010).

Cleomaceae is a cosmopolitan plant family comprising 18 genera and 150 to 200 species (Patchell et al. 2014). Cleomaceae species have been used to explore variation in petal pigments (Nozzolillo et al. 2010), flower and fruit morphology (Iltis 1957; Iltis 1958), and the evolution of floral symmetry (Patchell et al. 2011). The flowers exhibit great variation in morphological traits associated with attractants and rewards for pollinators including flower size and symmetry, petal colour, ultraviolet light reflection, floral fragrances, nectar glands, and pollen production (Cane 2008a; Erbar and Leins 1997; Iltis et al. 2011; Nozzolillo et al. 2010). However, the pollination biology of species belonging to this family is poorly understood.

Cleomella serrulata Pursh (Beeweed, previously known as Cleome serrulata - hereafter referred to as Cleomella) and Polanisia dodecandra L. (Clammyweed - hereafter referred to as Polanisia) are found in Alberta prairies. Although Cleomella is currently listed as a secure species in Alberta, its distribution appears to have substantially decreased over the years based on herbarium records. In contrast, Polanisia is listed as a rare species in Alberta and is vulnerable to local extirpation (Wallis 2001). Both species exhibit a mixed-mating system, in which plants can reproduce through self or cross-fertilization (Cane 2008a; Cruden and Lyon 1985; Wiens 1984). Cleomella was reported to attract pollinators from a wide variety of wild bee guilds and is also used extensively by managed pollinators, including Megachile rotundata F. and Apis mellifera L. in the United States (Cane 2008a). In addition, Cleomella seeds are sold and planted in the peripheries of agriculture areas, orchards, gardens and seed crops to promote pollinator populations. Despite the importance of Cleomella and Polanisia as forage for a number of bee species, information on the pollination biology of these plants is restricted to breeding biology of Cleomella (Cane 2008a) and morphological description for Polanisia (Iltis 1958). Although both 
species exhibit the same floral symmetry pattern, they differ in key morphological traits for pollinator attraction such as petal colour, inflorescence size and nectar display. Thus, we might expect variation in the communities of insects visiting both species and differences in the frequency of visits, because these flowers do not exhibit the same floral traits. Their floral morphology suggests that they may be pollinated by insects, probably bees, but it is uncertain which species of insects are effective pollinators.

The major goal of this study is to determine the pollination biology for wild populations of Cleomella and Polanisia in southern Alberta. To achieve this, we (i) described population densities and distributions of both plant species; (ii) determined their floral phenology; (iii) established time of stigma receptivity and anther dehiscence; and (iv) identified main flower visitors and their activity periods.

\section{MATERIALS AND METHODS}

Study site

This research was conducted during the summers of 2013 and 2014 at Suffield National Wild Area (Suffield), which comprises the largest remaining tract of native prairie in Alberta (458

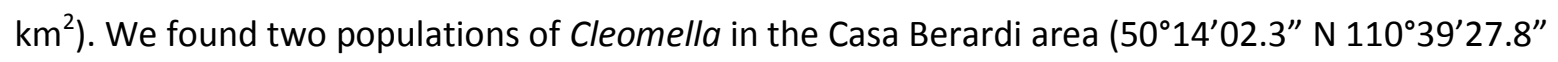
W, $668 \mathrm{~m})$ and the Komati area $\left(50^{\circ} 26^{\prime} 09.9^{\prime \prime} \mathrm{N} 110^{\circ} 31^{\prime} 36.6^{\prime \prime} \mathrm{W}, 707 \mathrm{~m}\right)$. Due to logistical issues, the Komati population was only sampled during 2013. We found one population of Polanisia in the Fish Creek area $\left(50^{\circ} 14^{\prime} 36.9^{\prime \prime} \mathrm{N} 110^{\circ} 39^{\prime} 42.5^{\prime \prime} \mathrm{W}, 682 \mathrm{~m}\right)$. The plants of both populations of Cleomella were growing in dry-mixed grassland on the roadside, while Polanisia plants were growing on sandy South Saskatchewan River bluffs (Supplementary Figure $\mathrm{S}^{1}{ }^{1}$ ).

Description of focal taxa

\footnotetext{
${ }^{1}$ Supplementary data are available through the journal Web site
} 
Cleomella serrulata is an annual herb. Leaves are alternate and trifoliate with slender elliptic leaflets (Moss 1983). Bracteate racemes contain numerous flowers and are located in the main stem and lateral branches (Figure 1). The inflorescences may have two kinds of hermaphroditic flowers with completely or incompletely developed pistils. At the beginning of the flowering season new flowers fail to fully develop pistils, but late in season inflorescences present both kinds of flowers (Cane 2008a). Flowers are monosymmetric; they have four green-reddish lanceolate sepals, four purple or soft pink petals rounded at the tip, with adaxial petals shorter than the abaxial ones (Figure 2). Flowers have six stamens longer than the petals, and a long bicarpellate gynoecium on a gynophore. An adaxial nectary is located between the petal and androecium whorls (Figure 1d); it is green, elongated and laminar with a three-toothed apex, and produces a drop of viscous nectar (Figure 1c). Fruits are cylindrical-oblong capsules with wrinkled ovoid blackish seeds (Moss 1983). In Alberta, the plants are distributed in mixed grasslands, pastures, roadsides, and stabilized sand dunes (Moss 1983).

Polanisia dodecandra is an annual herb. The stems vary from unbranched to basally branched, and are pubescent and densely covered by stipitate glands that produce a strong disagreeable smell (Iltis 1958; Moss 1983). Leaves are alternate and trifoliate with ovolanceolated leaflets. Bracteate racemes contain numerous flowers and are located in the main stem and lateral branches (Figure 3). Inflorescences have hermaphroditic flowers (Figure 3). Flowers are monosymmetric; they have four purple-greenish sepals and four white or white-pinkish petals notched at the tip, with adaxial petals longer than the abaxial ones (Figure 4). Flowers have 8 to 12 stamens variable in length, and a long bicarpellate gynoecium on a short gynophore (Figure 4). An adaxial nectary is located between the petal and androecium whorls (Figure $3 \mathrm{~d}$ ); it is obliquely truncated and concave in the apex, orange or reddish, and produces a drop of highly viscous nectar (Figure 3c). Fruits are erect, oblong capsules containing subspherical brownish seeds (Moss 
1983; Tucker and Vanderpool 2010). In Alberta, the plants are distributed in stream and river banks, dunes, and roadsides, generally growing in dry and sandy soils (Moss 1983).

Flowering phenology

Cleomella starts flowering in mid-late June and continues to flower until late August. The study performed by Cane (2008a) in Utah, found the flowers exhibited nocturnal anthesis and they opened $1-3 \mathrm{~h}$ after sunset. Flowers presented complete anther dehiscence and receptive stigmas $8 \mathrm{~h}$ after anthesis.

There are no published studies of Polanisia flowering phenology. To describe the floral phenology of $P$. dodecandra, we recorded time and duration of anthesis, time of stigma receptivity, and anther dehiscence for 20 randomly selected plants. We evaluated stigma receptivity in a greenhouse experiment, examining 2 stigmas per plant. Plants were grown at $24^{\circ} \mathrm{C}$ in long day conditions corresponding to 16 hours light and 8 hours dark (Department of Biological Sciences, University of Alberta). We tested stigma receptivity from excised pistils each day via a peroxidase test (Dafni 1992; Kearns and Inouye 1993). In the field, we recorded number of inflorescences per plant, number of flowers per inflorescences, fruit production per plant, and the length of flowering period.

Although the mating system of Cleomella (Cane 2008a) and Polanisia (Wiens 1984) were previously described, we attempted pollination limitation experiments using exclusion bags in 2013. Because the flowers are hermaphroditic we had to antherectomize flowers before anthesis to avoid self-pollination. However, most of the flowers died in the field due to mechanical damage. These experiments were not pursued further.

\section{Nectar volume and sugar concentration}

To determine the nectar volume available for pollinators and nectar sugar concentration, we performed a floral visitor exclusion experiment in 2014. To exclude floral visitors, we covered 
inflorescences with mesh bags for $24 \mathrm{~h}$ prior to sampling. We randomly selected 50 plants with large buds and covered the terminal inflorescences. We sampled nectar production during two consecutive sunny days and nectar samples were taken after 24 hours of nectar accumulation. For Cleomella, nectar volume and sugar concentration were sampled between 08:00 and 16:00 h. After 16:00 h most of the nectar had evaporated due to high temperatures, so no more sampling was conducted. For Polanisia, nectar volume and sugar concentration were measured from 08:00 $\mathrm{h}$ to $22: 00 \mathrm{~h}$ in two-hour intervals to determine if there are variations in nectar production rate and sugar concentration throughout the day. Floral nectar was extracted with a $10 \mu \mathrm{l}$ microcapillary tube in two-hour intervals. For each species, we calculated average nectar volume for 10 flowers per plant on 5 plants. Once the nectar volume was depleted the flowers did not produce more nectar. Thus, we used different flowers at every two-hour interval. We took nectar measurements from flowers closest to the inflorescence meristem following a clockwise direction and always used flowers at the same developmental stage (flowers open for one day after anthesis). Due to the small volume produced by each flower it was not possible to measure sugar concentration directly, thus, the nectar from 10 flowers was pooled to measure sugar concentration. Nectar volume was calculated following the method described by Dafni (1992), and Kearns and Inouye (1993). Nectar volume was then diluted 1:3 in distilled water due to the high nectar viscosity. After dilution, the sugar concentration was measured by a $0-30 \%$ refractometer (Extech Instruments). The values obtained from the refractometer were multiplied by the dilution factor to calculate the correct nectar concentration.

\section{Pollinator observations and visitation rates}

In 2013 , we performed a pilot study to collect and identify pollinator taxa visiting flowers. After experts helped verify taxonomic identifications, we made a visual guide with images of all taxa and used this to identify subsequent visitors. Every time that we collected a new taxon it was 
added to the visual guide. Male and female Hymenoptera often differ in their morphology and we included examples of each sex when possible to ensure that individuals were not identified as separate taxa.

To determine the insect visitation rates and their activity periods, we selected 20 groups of five plants for both Cleomella and Polanisia. The focal area of observed plants comprised of approximately $2 \mathrm{~m}^{2}$. Two people, who were familiar with insect taxonomy, performed the pollinator observations using the visual guide. Each person sat next to an adjacent plant group and recorded all insect visitors observed in 10-minute intervals and then we switched to another group. We observed the visitors for 20 hours from 06:00 to 02:00 $\mathrm{h}$. To perform the nocturnal observations we wore infrared headlights to illuminate the flowers. We did not perform observations between 02:00 to 06:00 h because of cool morning temperatures and scarcity of insect visitors. We recorded the total number of visits and the number of inflorescences visited. In addition, we described whether insects were foraging for nectar or pollen and the number of flowers and inflorescences visited. We collected representative plant vouchers and insect specimens for taxonomic identification, the latter of which included at least one specimen per observed taxa (241 specimens/2219 observed). Voucher specimens were deposited in the University of Alberta Vascular Plant Herbarium (ALTA) and E. H Strickland Entomological Museum, respectively.

\section{Data analysis}

We compared morphological characteristics of Cleomella and Polanisia using R ( $\mathrm{R}$ Development Core Team 2013) to determine if observed differences were significant. Specifically, we compared plant height, inflorescences per plant and flowers per inflorescence, fruit set, nectar volume, and nectar sugar concentration between the two species. For normally distributed variables, we performed a Student's t-test to compare trait differences between species in 
different years. For data that was not normally distributed, we performed a Mann-Whitney U test. We also performed the tests between years to determine if there was significant annual variation in the measured traits.

We calculated pollinator richness as the total number of taxa collected during the sampling period. To compare the difference in sampling effort between taxa and between years according to the number of observations obtained, we created a rarefaction curve for each plant species using Biodiversity Pro version 2 (McAleece et al. 1997).

To compare the pollinator community composition between plant species and sampling years, we performed a qualitative similarity analysis in Biodiversity-Pro version 2 (McAleece et al. 1997). We made a presence-absence matrix of insect visitors per plant population and sampling year and we performed a Jaccard coefficient analysis. The obtained matrix was grouped using UPGMA (Unweighted Pair Group Method with Arithmetic Mean).

\section{RESULTS}

\section{Description of Cleomella and Polanisia populations}

Both populations of Cleomella were in native mixed grassland growing along roadsides in densely aggregate clusters. The Komati population comprised 600 plants, while in Casa Berardi we found $\sim 500$ plants in 2013 and $~ 300$ plants in 2014; thus, the population size in Casa Berardi decreased by $40 \%$ from 2013 to 2014. Plant height ranged from $16 \mathrm{~cm}$ to $80 \mathrm{~cm}$; inflorescences per plant ranged from 1 to 64; flower number per inflorescence ranged from 2 to 301; and fruit set per plant ranged from 0 to 164 . In 2014, the Casa Berardi population had taller plants and more inflorescences per plant compared to the 2013 Casa Berardi and Komati populations, while the 2013 Casa Berardi population produced the highest fruit set relative to the 2014 Casa Berardi and Komati populations. The Komati plant population had the most flowers per inflorescence across 
sites (Table 1). Fruit set was significantly different between Casa Berardi 2013 and Komati populations (Supplementary Table $\mathrm{S}^{1}{ }^{1}$ ), although other morphological variables, including flower number, did not differ. However, plant height, inflorescences per plant, flowers per inflorescence and fruit set were significantly different between Casa Berardi 2013 and 2014 populations (Supplementary Tables S1-S2 ${ }^{1}$ ).

Polanisia plants were in dispersed clusters along river bluffs. The population consisted of $\sim 2500$ plants in 2013 , but only $\sim 600$ plants in 2014 , representing a remarkable reduction in population size of approximately $76 \%$. Plant height ranged from $4 \mathrm{~cm}$ to $58 \mathrm{~cm}$; inflorescences per plant ranged from 1 to 27 ; flower number per inflorescence ranged from 1 to 51 ; and fruit set per plant ranged from 1 to 103. In 2013, the population had, on average, taller plants, more inflorescences per plant, more flowers per inflorescence and a higher fruit set when compared to 2014 (Table 1). Plant height, inflorescences per plant, flowers per inflorescence and fruit set were significantly different in Fish Creek in 2013 compared to 2014 (Supplementary Tables S1-S2 ${ }^{1}$ ).

When comparing between species within years, all the variables differed significantly except the fruit set between the Komati Cleomella population and the Polanisia 2013 population (Supplementary Tables S1-S2 ${ }^{1}$ ).

Flowering phenology

Cleomella started flowering in early or late July. For both populations, flowering persisted until late August, and individual flowers were open for 5 days on average (Figure 1a-b). New flowers exhibited nocturnal anthesis, opening between 23:00 - 02:00 h; anthers released the pollen and stigmas became receptive $6-8$ hours after anthesis. At the beginning of the flowering season, most flowers had a short and presumably non-functional pistil. Therefore, these flowers did not produce any fruits. As the flowering season advanced, plants started to produce two kinds

\footnotetext{
${ }^{1}$ Supplementary data are available through the journal Web site
} 
of flowers: (i) flowers with short and non-functional pistils reaching 1/5 of the stamen length and (ii) flowers with long and fully-functional pistils that reach the stamen length (Figure 1d). When the plants had a high number of fruits, they again started producing primarily flowers with nonfunctional pistils.

Polanisia started flowering in late June or early July and the length of the flowering period was two months. Inflorescences persisted until late August and individual flowers lasted 7 days on average (Figure 3a-b). Flowers started to open shortly after the sunset between 23:00 - 01:00 h; however, the stigma became receptive 4 days on average before anthesis. Exerted pistils presented in floral buds were receptive after two days of bud development, with continuous receptivity during anthesis. The anthers started gradually releasing pollen after anthesis and the longest stamens were first to exhibit anther dehiscence, while anthers of shorter stamens were last to release pollen. This plant also produced flowers with short and non-functional pistils at the beginning of the flowering season, but, in contrast with Cleomella later in season, plants produced only flowers with long and completely functional pistils. Interestingly, some plants produced two kinds of completely distorted fruits: (i) fruits twisted over the longitudinal axis, and (ii) fruits with three or four sides instead of just two sides. These abnormal fruits did not produce viable seeds and in all of the cases seeds were aborted.

\section{Nectar volume and sugar concentration}

Cleomella flowers have a green nectar gland that started producing a viscous nectar drop two days before anthesis (Figure 1c-d). The nectar drop persisted approximately $15 \mathrm{~h}$ after anthesis from 01:00 - 16:00 h, but usually evaporated due to high daily temperatures or was removed by insects. Once the nectar evaporated or was removed, flowers did not secrete more nectar; however, during the flowering season nectar was always available for pollinators because new flowers opened daily (Figures $1 \mathrm{c}-\mathrm{d}$ ). Covered flowers produced the highest nectar volume of 
$0.85 \pm 0.96 \mu \mathrm{l}$ between 08:00 - 10:00 h; however variation in nectar volume production between flowers was high. After 10:00 h, nectar production decreased $68 \%$ on average, with nectar volume measuring $0.28 \pm 0.08 \mu \mathrm{l}$ and the variation between flowers was low (Figure 5a). Sugar concentration was relatively steady across time, but it was higher between 10:00 - 12:00 h (Figure 5b). In general, the average total sugar concentration in floral nectar was $40.80 \pm 7.68 \%$.

Polanisia flowers have an orange nectar gland (Figure 3c-d) that produced a highly viscous nectar drop, which was available to pollinators during anthesis (Figure 3d). The nectar drop persisted for approximately $48 \mathrm{~h}$ after anthesis. Covered flowers produced the highest nectar volume, $0.63 \pm 0.32 \mu \mathrm{l}$ between 10:00 - 12:00 h; however variation in nectar volume production between flowers was high. After 14:00 h nectar production decreased $60 \%$ on average, the nectar volume was $0.25 \pm 0.06 \mu \mathrm{l}$ and the variation between flowers was low (Figure $5 \mathrm{c}$ ). The sugar concentration was steady between 08:00 - 14:00 $\mathrm{h}$ and it decreased between 14:00 - 16:00 h; interestingly the sugar concentration increased to a maximum peak between 20:00 - 22:00 $\mathrm{h}$ corresponding to $43.32 \pm 4.74 \%$ (Figure $5 \mathrm{~d}$ ). The sugar concentration differed significantly between species, while the nectar volume did not (Supplementary Table S $1^{1}$ ).

\section{Pollinator observations and visitation rates}

We observed 2211 insect and 8 spider visitors corresponding to 8 orders, 48 families and 150 taxa visiting the two plant species for the total survey period (Supplementary Table S3 ${ }^{1}$ ). For the Cleomella population in Komati, we recorded 85 taxa and 442 visits, while in Casa Berardi we recorded 76 taxa and 276 visits in 2013, and 96 taxa and 1327 visits in 2014. Thus, visitor richness and insect visits increased $20.8 \%$ and $79.2 \%$ respectively in 2014 (Supplementary Table S3 ${ }^{1}$ ). For Polanisia, we recorded 44 taxa and 81 visits in 2013, while we recorded 32 taxa and 93 visits in 2014. Furthermore, richness of visitors was $27.3 \%$ higher in 2013 , while the insect visits were

\footnotetext{
${ }^{1}$ Supplementary data are available through the journal Web site
} 
12.9\% higher in 2014 (Supplementary Table S3 ${ }^{1}$ ). The rarefaction analysis indicated that we did not get the number of expected pollinator species for either plant population based on the obtained rarefaction curves, which were far from the asymptote except for the Cleomella Casa Berardi 2014 population (Supplementary Figure $\mathrm{S}^{1}$ ).

The average visitation rate in Cleomella populations was 4.52 insects per plant per hour (Supplementary Tables S3-S4 ${ }^{1}$ ). We found no significant differences in the number of pollinator visits between Casa Berardi and Komati populations in 2013 (Supplementary Table S1 ${ }^{1}$ ). However, pollinator visitation number was significantly different between Casa Berardi in 2013 and 2014 (Supplementary Table $\mathrm{S}^{1}$ ). Hymenoptera had the highest richness in both sampling periods followed by Diptera and Lepidoptera (Figure 6a-b). Within Hymenoptera, bee families presented the highest richness and Formicidae the highest number of visits. The most frequent visitors excluding permanent residents were Ammophila azteca (sphecid wasp), Bombus borealis, and $B$. ternarius (Supplementary Table $\mathrm{S4}^{1}$ ). Most Apidae visited the plants for pollen but occasionally collected nectar too, while other hymenopterans visited the plants for nectar and transferred pollen passively between flowers. Bombus borealis, one of the most frequent pollinators, represented $32.29 \%$ of overall visits. Bombus borealis started visiting the flowers at 07:00 $\mathrm{h}$, and they exhibited higher visitation rates at 09:00 $\mathrm{h}$ and 14:00 $\mathrm{h}$. After 15:00 $\mathrm{h}$ the bees did not visit the plants at all (Supplementary Figure $S 3^{1}$ ). In contrast, B. ternarius, another common visitor, started visiting the flowers at 06:00 $\mathrm{h}$ and represented $38.61 \%$ of overall visits (Supplementary Table $\mathrm{S}^{1}{ }^{ }$). Bumblebees had three high frequency visitation periods: 08:00 $\mathrm{h}, 10: 00 \mathrm{~h}$ and 21:00 $\mathrm{h}$, and the frequency of visits decreased rapidly between 12:00 $\mathrm{h}$ and 19:00 $\mathrm{h}$ (Supplementary Figure $S 3^{1}$ ). Both bumblebee species were visiting plants for nectar and pollen, touched anthers and pistils and flew between plants, acting as potential pollen vectors. In addition, we observed the

\footnotetext{
${ }^{1}$ Supplementary data are available through the journal Web site
} 
first nocturnal visitors for Cleomella, which includes four Noctuidae taxa, a crambid and an erebid moth (Supplementary Table S3 ${ }^{1}$ ). We collected Synnervus plagiatus (sand wasp), which has not previously been recorded in Alberta, and Bombus griseocolis, only the second individual collected in Alberta (Supplementary Table S3 ${ }^{1}$ ), and only recently reported in the province by Sheffield et al. (2014). We also observed Formicidae taxa feeding on nectar and pollen as well as residing in plants so they could occasionally act as pollination vectors. In addition, we observed Nitidulidae taxa that used the plant as permanent residents and completed their breeding cycle in the plant, which caused loss of fruit set. Furthermore, we found Phymata americana (ambush bug), and Thomisidae spiders (Supplementary Table $S 3^{1}$ ). These taxa, which were not likely to be effective pollinators, actively chased away other flower visitors and preyed upon syrphid flies, sphecid and pompilid wasps, small bees, and butterflies.

The average visitation rate for Polanisia was 1.41 per plant per hour (Supplementary Tables S3-S4 ${ }^{1}$ ). We did not find significant differences in pollinator visit number between sampling periods (Supplementary Table $\mathrm{S1}^{1}$ ). Hymenoptera had the highest richness and number of visits in 2013 followed by Diptera, Lepidoptera and Coleoptera (Figure 7a-b). In contrast, Diptera and Hymenoptera had the highest richness in 2014, while Diptera had the highest number of visits (Figure 7a-b). Within Hymenoptera, bee families presented the highest richness. The most frequent taxa were Microbembex monodonta (sand wasp), Perdita sp. 1, and Syrphidae sp. 4 (Supplementary Table $\mathrm{S} 4^{1}$ ). Microbembex monodonta represented $8.33 \%$ of overall visits and started visiting the plants at 08:00 h, with highest activity at 09:00 h, but their frequency of visits decreased after 13:00h (Supplementary Figure $S 4^{1}$ ). Syrphidae sp. 4, another common pollinator, represented $18.75 \%$ of overall visits. Hover flies visited flowers from 09:00 h, with peak visitation rates at 10:00 $\mathrm{h}$ and 13:00 h; after 14:00 $\mathrm{h}$ the visit activity ceased completely (Supplementary

\footnotetext{
${ }^{1}$ Supplementary data are available through the journal Web site
} 
Figure $S 4^{1}$ ). Sand wasps and hover flies were feeding on nectar and pollen from different plants, acting as potential vectors for cross-pollination. We also found Formicidae taxa feeding on nectar and pollen, although their frequency was lower when compared with ants on Cleomella (Supplementary Table S3 ${ }^{1}$ ).

When we compared the pollinator visitor composition between species across sampling periods, the Jaccard similarity analysis showed that Polanisia populations and Cleomella populations grouped together; in other words, different populations of Polanisia had more similar pollinator communities than a population of Polanisia and a population of Cleomella (Figure 8). Jaccard index values range from 0 to 100 , where 0 indicated no taxa shared between communities and 100 represent identical communities. The similarity index of Polanisia populations was 26.67\%, while Cleomella Casa Berardi and Komati populations clustered together and the similarity index was $47.27 \%$. The similarity values indicate that Polanisia populations had fewer taxa in common when compared with Cleomella populations, which shared more taxa.

\section{DISCUSSION}

\section{Distribution of focal species}

Native prairies are one of the most endangered ecosystems in North America due to anthropogenic activity (Fuhlendorf et al. 2002; Mlot 1990; Samson and Knopf 1994). Much of the natural vegetation was gradually replaced by tame pastures or by crop production, leading to a loss in the biodiversity of native flora and fauna (Fuhlendorf et al. 2002; Kevan 1999; Samson and Knopf 1994). More than 70\% of Canadian native prairies were transformed into rangelands or crops before the 1990s (Sheffield et al. 2014). In Alberta, Suffield NWA is the largest remnant of native prairie, but grasses are the dominant vegetation type, while forbs are scarce. Native flowering plants such as Cleomella and Polanisia may therefore represent an important source of 
forage for pollinators. Despite many potential habitats for Cleomella in Alberta, it is restricted to remnant grasslands, disturbed sites and roadsides (Moss 1983). The plants form a densely aggregated cluster, which is visited by a broad spectrum of pollinators. On the other hand, Polanisia is located on the western and northern limit of its distribution and although the species also forms densely aggregated clusters, the rate of visits by pollinators was $92 \%$ lower when compared with Cleomella. The study population of Polanisia was growing on a steep slope in an unstable sandy area, and was subjected to strong winds, which could deter accessibility of these plants by insects. Fluctuations in population size could be the result of annual variation in environmental factors, including the availability of foraging resources for pollinators.

Both Cleomella and Polanisia grow in disturbed areas or in areas where colonization by other plant species is difficult. These species have been used for restoration projects on overgrazed lands, for soil stabilization in disturbed areas, and to rehabilitate rangelands after fires in western regions of North America (Cane 2008b; Smith et al. 2010). But once the soil has been restored, these plants are naturally replaced by more competitive forbs (Cane 2008a, b; Smith et al. 2010). According to herbarium records, years ago both plants had a wider distribution in Alberta, but the populations were small and localized. However, after visiting the locations where plants had been previously reported, the populations were no longer there. Further ecological studies are needed to determine if competitive exclusion or habitat losses are a determining factor in the scarcity of Cleomella and Polanisia populations in Alberta.

Flowering phenology and mating systems of focal species

Both Cleomella and Polanisia have a mixed-mating system, exhibiting floral characteristics to attract pollinators and promote cross-pollination, as well as strategies to avoid self-pollination (Cane 2008a; Cruden and Lyon 1985; Wiens 1984). For example, the Polanisia stigma is receptive days prior to the release of pollen from anthers. The low rate of insect visits and the location of 
plants could be favoring self-pollination in this population. However, selfing in Polanisia may result in a high rate of inbreeding in the population, as suggested by several plants that produced fruits with abnormal morphology and unviable seeds. Poor seed production may be contributing to Polanisia's relative rarity compared to Cleomella.

Both species produce staminate flowers early in the flowering period. The production of staminate flowers is a mechanism to differentially allocate resources to male and female functions, which allows plants to control the timing of fruit initiation and production (Lloyd and Bawa 1984; Miller and Diggle 2007). In Cleomella, once the plants produce many fruits, they start to produce staminate flowers again, while Polanisia plants switch to producing hermaphrodite flowers later in the season. Polanisia plants produced fewer inflorescences, flowers per inflorescence, and fruits when compared with Cleomella. In addition, the flowers received a low visitation rate by pollinators. Thus, later in the season, the plants likely produce more fruits to ensure their reproductive success.

Focal species produce high nectar volume and moderately concentrated nectar sugars

Even though the nectar gland of Cleomella is inconspicuous, it produces a substantial volume of nectar for pollinators. The highest nectar volume was produced between 08:00 and 10:00, which is consistent with the high frequency of pollinators. Most visits were conducted from 07:00 until 13:00, when frequency of visits decreased due to high temperatures, although plants continued receiving insect visits at lower frequencies until late at night. Sugar concentration in nectar was steady in Cleomella. The moderate sugar concentrations produced by the flowers attract a wide spectrum of pollinators and Hymenoptera and Diptera taxa were the most common visitors for this plant.

Despite the conspicuous nectar gland and the UV reflectance patterns in the nectar, Polanisia received few insect visits during the sampling period. The highest nectar volume was 
produced between 10:00 - 12:00, which is directly related with the number of insect visits performed at this time. Surprisingly, the highest sugar concentration was found between 20:00 22:00, but no crepuscular or nocturnal insects were observed visiting the plants at this time. This may be due to the plant's distribution; they are growing on the Western and northern boundary of the species' range, which may be inconsistent with the optimal pollinator community.

\section{Pollinator communities are diverse and differ between species}

Cleomella and Polanisia attracted a wide spectrum of visitors, the most abundant and diverse being from Hymenoptera, Diptera, and Lepidoptera. The focal species shared most of the visitor taxa including bees, wasps, butterflies and moths. Although six taxa visited exclusively Polanisia, overall Cleomella attracted more insects than Polanisia. This difference may be due primarily to the pink petal colour, the higher number of open flowers, and the greater number of flowers forming inflorescences of Cleomella, which exhibit a larger display than Polanisia. Species exhibiting a larger floral display can attract a greater number of visitors when compared with similar species with smaller floral displays (Galloway et al. 2002; Klinkhamer and de Jong 1990; Schmid-Hempel and Speiser 1988). Most of the taxa visiting both plants are generalist pollinators including polylectic bees such as halictid bees and bumblebees. However, we also observed oligolectic bees such as Andrena and Perdita species. Perdita species have been reported as oligolectic bees for Cleomella (Cane 2008a) and these species collected pollen actively in both Cleomella and Polanisia, but we did not observe them in the surrounding plants. There are 298 bee species reported for Alberta prairies (Sheffield et al. 2014) and bees visiting Cleomella and Polanisia account for $8.38 \%$ of the bee fauna reported for Alberta. Our results therefore suggest that these plants contribute to supporting a large and variable community of pollinators. Perhaps unsurprising based on morphology and distribution, the focal species differ in key floral traits for pollinator attraction. Cleomella petal colour, which varies from pink to purple, 
might make them more visible to pollinators. Surprisingly, although the nectar of Polanisia flowers produces UV reflection and the nectar gland is vividly colored, the visitation rate was lower than Cleomella flowers. Nectar volume and sugar concentration were higher in Cleomella than in Polanisia, which correlates with the higher visitation frequencies observed in Cleomella. However, the location of the populations might also have an effect on visitation frequencies. Cleomella plants were located in sites that gave pollinators easy access, while Polanisia plants were located in a river bluff subject to strong winds that make pollinator access difficult. In addition, differences between the visitation frequencies of both species could be due to other factors that we did not consider here such as pollen limitation, floral fragrances, flower constancy, and the presence of other floral species that could be competing or facilitating pollinator visits.

Two pollinators that were predicted to visit Cleomella and Polanisia were conspicuously absent. Bombus occidentalis has been recorded in the area in past studies (Hobbs 1968) and was at one time very common. However, B. occidentalis populations are declining in Western North America, likely due to pathogen infections and habitat fragmentation (Cameron et al. 2011), and the species has recently been listed as endangered in Canada. We also recorded only two visits of Apis mellifera to the plants. The low frequency of visits performed by A. mellifera is likely due to the distance from where the managed hives are kept by beekeepers. Overall, the bee fauna visiting Cleomella in Alberta is slightly less rich than that reported for populations in Utah, United States (Cane 2008a, b). Our results suggest that Cleomella and Polanisia provide important food resources that help support a rich community of pollinators including different bee guilds, flies, butterflies and other insects.

Although flowers of both species are anthetic at night, we did not observe a high visitation frequency of nocturnal pollinators. Nocturnal anthesis is also presented in Cleomella lutea (Cane 2008a) and Cleome spinosa (Dafni et al. 1987). Interestingly, crepuscular and nocturnal moths 
visited Cleomella, but their frequency was lower when compared with diurnal pollinators and they were active only between 11:00 - 01:00. After 01:00 the temperature decreased and no floral visitors were observed. Cane (2008a), suggested that nocturnal anthesis could be an ancestral trait in Cleomaceae species, but further evolutionary studies are needed to test this interesting assumption.

Implications for agriculture and conservation

Generalist native plants that attract a diverse range of pollinators are essential for the conservation of wild pollinators, particularly in habitats where flowers are a limited resource. In addition, native plants provide much needed dietary diversity for managed pollinators and are an important alternative food resource for honey bees in crop margins (Garibaldi et al. 2014). Cleomella and Polanisia may be good candidate species to increase floral resources in prairie agroecosystems because they grow in disturbed areas and could be planted in field margins or along tracks and roads next to crop areas to support managed and native pollinator communities. Furthermore, Cleomella and Polanisia could be used in restoration projects after fires or for industrial use in Alberta prairies and grasslands, since they are ruderal plants, and grow well in disturbed areas (Cane 2008a, b; Smith et al. 2010). Therefore, Cleomella and Polanisia could be used to promote and maintain the diversity of wild pollinators not only in range and croplands, but also in parklands, orchards and gardens, thereby providing an essential ecosystem service.

Pollinators are threatened by habitat transformation in many ecosystems, but prairie pollinators in North America are particularly at risk because anthropogenic disturbance is high (Kevan 1999). Promoting the conservation of native plants in natural grasslands will support biodiversity of pollinators and ensure they continue to provide pollination services to natural and agricultural ecosystems (Altieri 1999; Duelli et al. 1999; Kevan 1999). 


\section{Acknowledgements}

This research was funded by ACA Grants in Biodiversity (supported by the Alberta Conservation Association), a NSERC Discovery Grant held by Jocelyn C. Hall, and a Colciencias "Generación Bicentenario" scholarship. We thank Canadian Forces Base Suffield for granting access to the study area. Thanks to Benjamin Taylor, range biologist Suffield CFB, for his logistical help during the project, as well as Jared Bernard and Jenny Kleininger for field assistance. Thanks to Ron Linowski, Linda Linowski and Jana Vamosi who kindly provided location coordinates of focal species populations. Thanks to Cory Sheffield, Ashton Sturm, Felix Sperling, Gary Anweiler, Matthias Buck and Tyler Cobb for help with insect identification. Thanks to Dorothy Fabijan for assistance with plant voucher preparation. We would also like to thank members of the Manson lab and three anonymous reviews for feedback on earlier drafts of this manuscript.

\section{References}

Altieri, M.A. 1999. The ecological role of biodiversity in agroecosystems. Agric., Ecosyst. Environ. 74(1-3): 19-31. doi: 10.1016/S0167-8809(99)00028-6.

Cameron, S.A., Lozier, J.D., Strange, J.P., Koch, J.B., Cordes, N., Solter, L.F., and Griswold, T.L. 2011. Patterns of widespread decline in North American bumble bees. Proc. Natl. Acad. Sci. 108(2): 662667. doi: $10.1073 /$ pnas.1014743108.

Cane, J.H. 2008a. Breeding biologies, seed production and species-rich bee guilds of Cleome lutea and Cleome serrulata (Cleomaceae). Plant Species Biology 23(3): 152-158. doi: 10.1111/J.14421984.2008.00224.X. 
Cane, J.H. 2008b. Pollinating bees crutial to farming wildflower seed for U.S. habitat restoration. In Bee pollination in agricultural ecosystems. Edited by R.R. James and T.L. Pitts-Singer. Oxford University Press, New York. pp. 48 - 64.

Cruden, R.W., and Lyon, D.L. 1985. Patterns of biomass allocation to male and female functions in plants with different mating systems. Oecologia 66(2): 299-306. doi: 10.1007/BF00379868.

Dafni, A. 1992. Pollination ecology: a practical approach. IRL Press at Oxford University Press, Oxford. pp. 250.

Dafni, A., Eisikowitch, D., and Ivri, Y. 1987. Nectar flow and pollinators' efficiency in two cooccurring species of Capparis (Capparaceae) in Israel. PI. Syst. Evol. 157(3-4): 181-186.

Duelli, P., Obrist, M.K., and Schmatz, D.R. 1999. Biodiversity evaluation in agricultural landscapes: above-ground insects. Agric., Ecosyst. Environ. 74(1-3): 33-64. doi: 10.1016/S01678809(99)00029-8.

Erbar, C., and Leins, P. 1997. Studies on the early floral development in Cleomoideae (Capparaceae) with emphasis on the androecial development. PI. Syst. Evol. 206(1-4): 119-132. doi: 10.1007/BF00987944.

Free, J.B. 1993. Insect pollination of crops. Academic Press, London. pp. 768.

Fuhlendorf, S.D., Zhang, H., Tunnell, T.R., Engle, D.M., and Cross, A.F. 2002. Effects of grazing on restoration of southern mixed Prairie soils. Restoration Ecology 10(2): 401-407. doi:

10.1046/j.1526-100X.2002.00013.x.

Galloway, L.F., Cirigliano, T., and Gremski, K. 2002. The contribution of display size and dichogamy to potential geitonogamy in Campanula americana. Int. J. Plant Sci. 163(1): 133-139. doi: $10.1086 / 324556$

Garibaldi, L.A., Carvalheiro, L.G., Leonhardt, S.D., Aizen, M.A., Blaauw, B.R., Isaacs, R., Kuhlmann, M., Kleijn, D., Klein, A.M., Kremen, C., Morandin, L., Scheper, J., and Winfree, R. 2014. From 
research to action: enhancing crop yield through wild pollinators. Frontiers in Ecology and the Environment 12(8): 439-447. doi: 10.1890/130330.

Hegland, S.J., and Totland, $\varnothing .2005$. Relationships between species' floral traits and pollinator visitation in a temperate grassland. Oecologia 145(4): 586-594. doi: 10.1007/s00442-005-0165-6. Herrera, C.M. 1996. Floral traits and plant adaptation to insect pollinators: a devil's advocate approach. In Floral biology. Springer. pp. 65-87.

Hobbs, G.A. 1968. Ecology of species of Bombus (Hymenoptera: Apidae) in southern Alberta: VII. Subgenus bombus. The Canadian Entomologist 100(02): 156-164. doi: 10.4039/Ent100156-2. Iltis, H.H. 1957. Studies in the Capparidaceae. III. Evolution and phylogeny of the western North American Cleomoideae. Ann. Mo. Bot. Gard. 44(1): 77-119. doi: 10.2307/2394679.

Iltis, H.H. 1958. Studies in the Capparidaceae-IV. Polanisia Raf. Brittonia 10(2): 33-58. doi: $10.2307 / 2804916$.

Iltis, H.H., Hall, J.C., Cochrane, T.S., and Sytsma, K.J. 2011. Studies in the Cleomaceae I. On the separate recognition of Capparaceae, Cleomaceae, and Brassicaceae. Ann. Mo. Bot. Gard. 98(1): 28-36. doi: $10.3417 / 2007017$.

Kearns, C.A., and Inouye, D.W. 1993. Techniques for pollination biologists. University Press of Colorado, Colorado. pp. 583.

Kevan, P.G. 1999. Pollinators as bioindicators of the state of the environment: species, activity and diversity. Agric., Ecosyst. Environ. 74(1-3): 373-393. doi: 10.1016/\$0167-8809(99)00044-4.

Klein, A.-M., Vaissière, B.E., Cane, J.H., Steffan-Dewenter, I., Cunningham, S.A., Kremen, C., and Tscharntke, T. 2007. Importance of pollinators in changing landscapes for world crops. Proc. R. Soc. B: Biol. Sci. 274(1608): 303-313. doi: 10.1098/rspb.2006.3721. 
Klinkhamer, P.G., and de Jong, T.J. 1990. Effects of plant size, plant density and sex differential nectar reward on pollinator visitation in the protandrous Echium vulgare (Boraginaceae). Oikos: 399-405. doi: 10.2307/3565970.

Lloyd, D.G., and Bawa, K.S. 1984. Modification of the gender of seed plants in varying conditions. Evol. Biol. 17: 255-338.

McAleece, N., Gage, J.D.G., Lambshead, P.J.D., and Paterson, G.L.J. 1997. BioDiversity Professional statistics analysis software.

Miller, J.S., and Diggle, P.K. 2007. Correlated evolution of fruit size and sexual expression in andromonoecious Solanum sections Acanthophora and Lasiocarpa (Solanaceae). Am. J. Bot. 94(10): 1706-1715. doi: 10.3732/ajb.94.10.1706.

Mlot, C. 1990. Restoring the prairie. BioScience 40(11): 804-809. doi: 10.2307/1311481.

Moldenke, A.R. 1976. California pollination ecology and vegetation types. Phytologia 34(4). Moss, E.H. 1983. Flora of Alberta: a manual of flowering plants, conifers, ferns, and fern allies found growing without cultivation in the Province of Alberta, Canada. University of Toronto Press. Nozzolillo, C., Amiguet, V.T., Bily, A.C., Harris, C.S., Saleem, A., Andersen, O.M., and Jordheim, M. 2010. Novel aspects of the flowers and floral pigmentation of two Cleome species (Cleomaceae), $C$. hassleriana and C. serrulata. Biochem. Syst. Ecol. 38(3): 361-369. doi: 10.1016/J.Bse.2010.03.005. Patchell, M.J., Bolton, M.C., Mankowski, P., and Hall, J.C. 2011. Comparative floral development in Cleomaceae reveals two distinct pathways leading to monosymmetry. Int. J. Plant Sci. 172(3): 352365. doi: $10.1086 / 658158$.

Patchell, M.J., Roalson, E.H., and Hall, J.C. 2014. Resolved phylogeny of Cleomaceae based on all three genomes. Taxon 63(2): 315-328. doi: 10.12705/632.17.

Proctor, M.C.F., Yeo, P., and Lack, A. 1996. The natural history of pollination. Timber Press, Portland, Or. pp. 479. 
R Development Core Team. 2013. R: A language and environment for statistical computing. $R$ Foundation for Statistical Computing, Vienna, Austria.

Samson, F., and Knopf, F. 1994. Prairie conservation in North America. BioScience 44(6): 418-421. doi: $10.2307 / 1312365$.

Schmid-Hempel, P., and Speiser, B. 1988. Effects of inflorescence size on pollination in Epilobium angustifolium. Oikos: 98-104. doi: 10.2307/3565669.

Sheffield, C.S., Frier, S.D., and Dumesh, S. 2014. The bees (Hymenoptera: Apoidea, Apiformes) of the Prairies eEcozone, with comparisons to other grasslands of Canada. In Arthropods of Canadian Grasslands. Edited by D.J. Giberson and H.A. Carcamo. Biological Survey of Canada. pp. 427-467. Smith, F.S., Maywald, P.D., Lloyd-Reilley, J., Maher, S.D., Pawelek, K.A., Scott Jr, A.W., and Garza, J. 2010. Zapata germplasm rio grande Clammyweed. Native Plants Journal 11(3): 269-273. doi: 10.1353/npj.2010.0010.

Tucker, G.C., and Vanderpool, S.S. 2010. Cleomaceae. In Flora of North America North of Mexico. Edited by F.N.A.E. Committee. Oxford University Press, New York. pp. 199 - 223.

Wallis, C. 2001. Proposed protocols for inventories of rare plants of the Grassland Natural Region. Alberta Sustainable Resource Development, Fish and Wildlife Service, Edmonton. pp. 305. Waser, N.M., Chittka, L., Price, M.V., Williams, N.M., and Ollerton, J. 1996. Generalization in pollination systems, and why it matters. Ecology 77(4): 1043-1060. doi: 10.2307/2265575. Wiens, D. 1984. Ovule survivorship, brood size, life history, breeding systems, and reproductive success in plants. Oecologia 64(1): 47-53. doi: 10.1007/BF00377542.

Willmer, P. 2011. Pollination and floral ecology. Princeton University Press, Princeton, N.J. pp. 778. 
Table 1. Means and standard deviations of plant height, flowering, and fruit set measurements for Cleomella serrulata and Polanisia dodecandra at Casa Berardi, Komati, and Fish Creek area. Data collected in 2013 and 2014 ( $\mathrm{N}=100$ per site).

\begin{tabular}{lcccc}
\hline & $\begin{array}{c}\text { Plant height } \\
(\mathbf{c m})\end{array}$ & $\begin{array}{c}\text { Inflorescences } \\
\text { per plant }\end{array}$ & $\begin{array}{c}\text { Flowers per } \\
\text { inflorescence }\end{array}$ & Fruit set \\
\hline C. serrulata Casa Berardi 2013 & $43.85 \pm 10.70$ & $9.07 \pm 5.58$ & $6.65 \pm 5.39$ & $50.78 \pm 40.56$ \\
C. serrulata Casa Berardi 2014 & $47.29 \pm 13.85$ & $13.35 \pm 11.96$ & $20.08 \pm 12.61$ & $27.52 \pm 32.69$ \\
C. serrulata Komati 2013 & $41.20 \pm 19.20$ & $9.15 \pm 10.80$ & $22.18 \pm 14.08$ & $28.37 \pm 32.64$ \\
P. dodecandra Fish Creek 2013 & $35.30 \pm 8.51$ & $3.98 \pm 3.09$ & $14.44 \pm 6.73$ & $22.84 \pm 13.61$ \\
P. dodecandra Fish Creek 2014 & $17.10 \pm 7.96$ & $2.23 \pm 1.95$ & $11.28 \pm 5.38$ & $14.52 \pm 14.60$ \\
& & & & \\
\hline
\end{tabular}


Figure 1. Photos of Cleomella serrulata. (A) Terminal raceme inflorescence bearing abundant small flowers. (B) Bombus ternarius and Formica sp. visiting flowers. (C) Nectar droplet. (D) Flower with petals removed to expose the nectary at the base. Scale bars: $1 \mathrm{~mm}$.

Figure 2. Cleomella serrulata flower. (A) Frontal view. (B) Lateral view. Scale bar: $1 \mathrm{~cm}$.

Figure 3. Photos of Polanisia dodecandra. (A) Terminal raceme inflorescence bearing abundant small flowers. (B) Lasioglossum sp. collecting pollen from the anther. (C) Nectar droplet. (D) Flower with petals removed to expose the nectary at the base. Scale bars: $1 \mathrm{~mm}$.

Figure 4. Polanisia dodecandra flower. (A) Frontal view. (B) Lateral view. Scale bar: $1 \mathrm{~cm}$.

Figure 5. Nectar production in (A) Cleomella serrulata, (B) Polanisia dodecandra, and sugar concentration in (C) Cleomella serrulata, (D) Polanisia dodecandra at different time intervals. Error bars show standard deviation $(\mathrm{N}=50)$.

Figure 6. Richness and number of insect visits for Cleomella serrulata flowers in 2013 and 2014 at Komati (KM) and Casa Berardi (CB) areas. (A) Species richness per insect order. (B) Number of visits per insect order.

Figure 7. Richness and number of insect visits for Polanisia dodecandra flowers in 2013 and 2014 at Fish Creek (FC) area. (A) Species richness per insect order. (B) Number of visits per insect order.

Figure 8. Jaccard similarity index dendrogram. $\mathrm{CB}=\mathrm{Casa}$ Berardi, $\mathrm{FC}=$ Fish Creek, $\mathrm{KM}=$ Komati. 

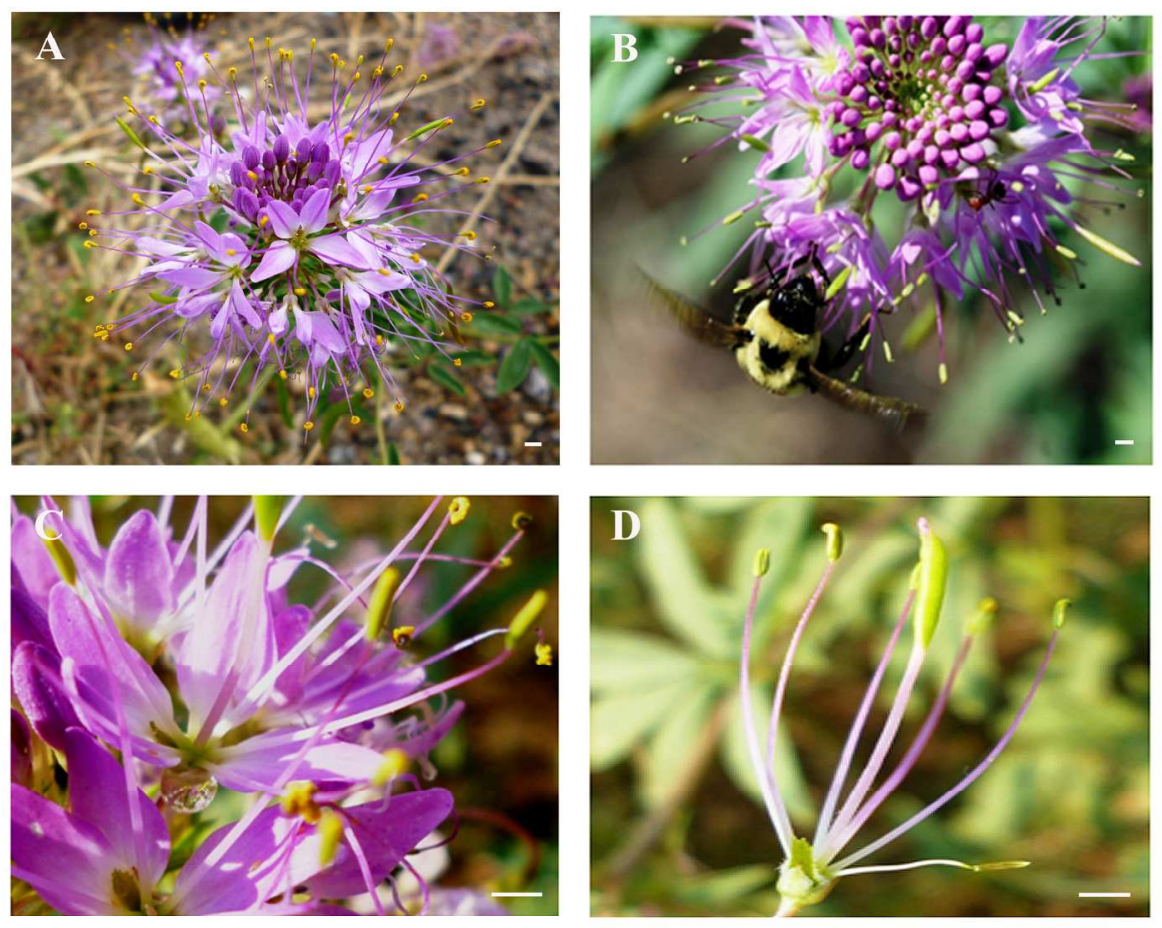

Photos of Cleomella serrulata. (A) Terminal raceme inflorescence bearing abundant small flowers. (B) Bombus ternarius and Formica sp. visiting flowers. (C) Nectar droplet. (D) Flower with petals removed to expose the nectary at the base. Scale bars: $1 \mathrm{~mm}$. $204 \times 177 \mathrm{~mm}(300 \times 300$ DPI) 
A

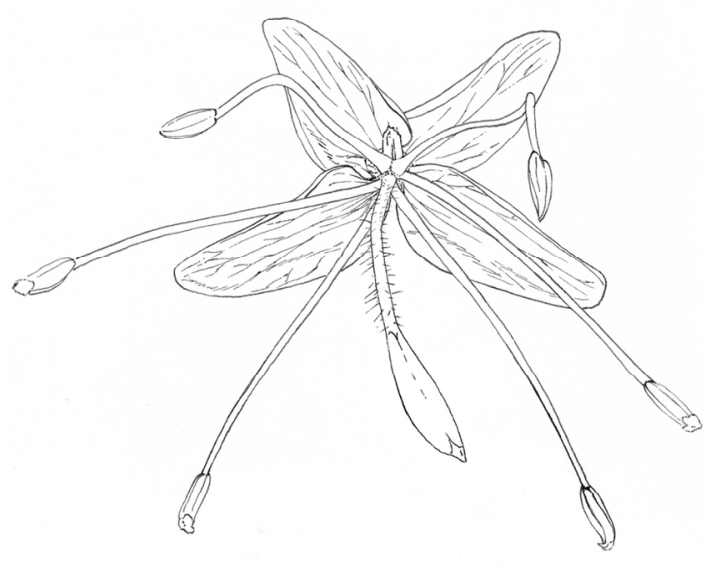

Cleomella serrulata flower. (A) Frontal view. (B) Lateral view. Scale bar: $1 \mathrm{~cm}$. $68 \times 37 \mathrm{~mm}(600 \times 600 \mathrm{DPI})$
B

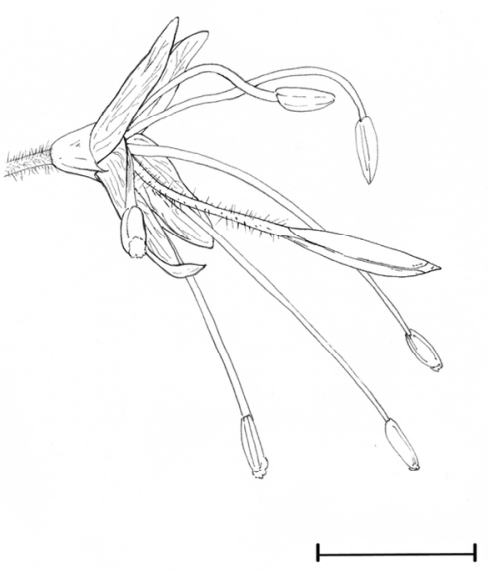



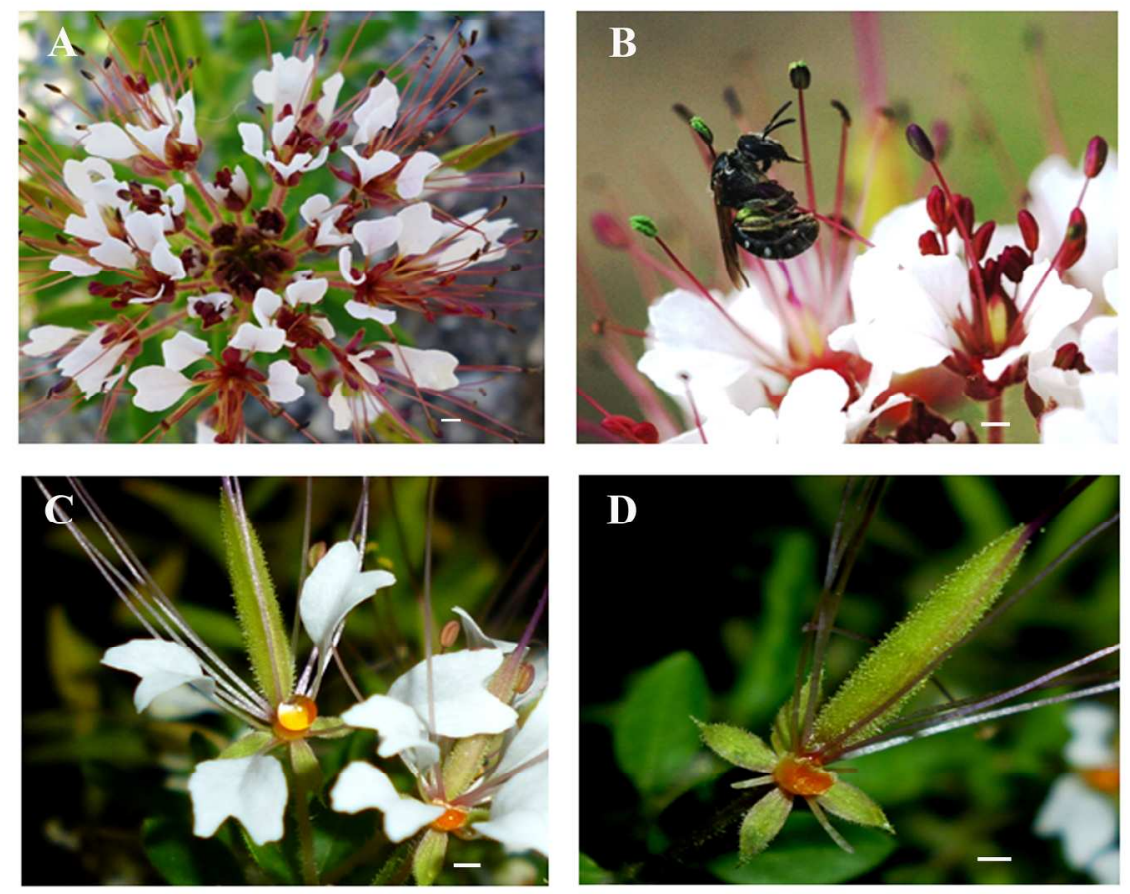

Photos of Polanisia dodecandra. (A) Terminal raceme inflorescence bearing abundant small flowers. (B) Lasioglossum sp. collecting pollen from the anther. (C) Nectar droplet. (D) Flower with petals removed to expose the nectary at the base. Scale bars: $1 \mathrm{~mm}$. $204 \times 177 \mathrm{~mm}(300 \times 300$ DPI $)$ 
A

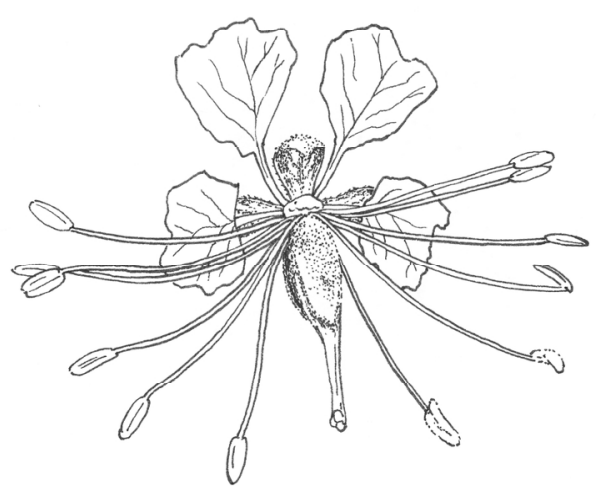

B

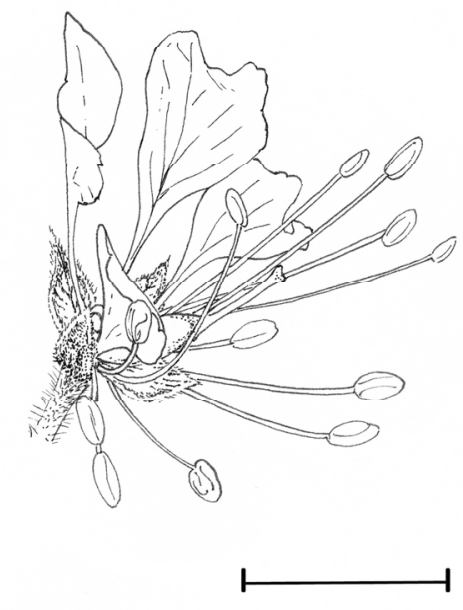

Polanisia dodecandra flower. (A) Frontal view. (B) Lateral view. Scale bar: $1 \mathrm{~cm}$. $85 \times 46 \mathrm{~mm}(600 \times 600 \mathrm{DPI})$ 

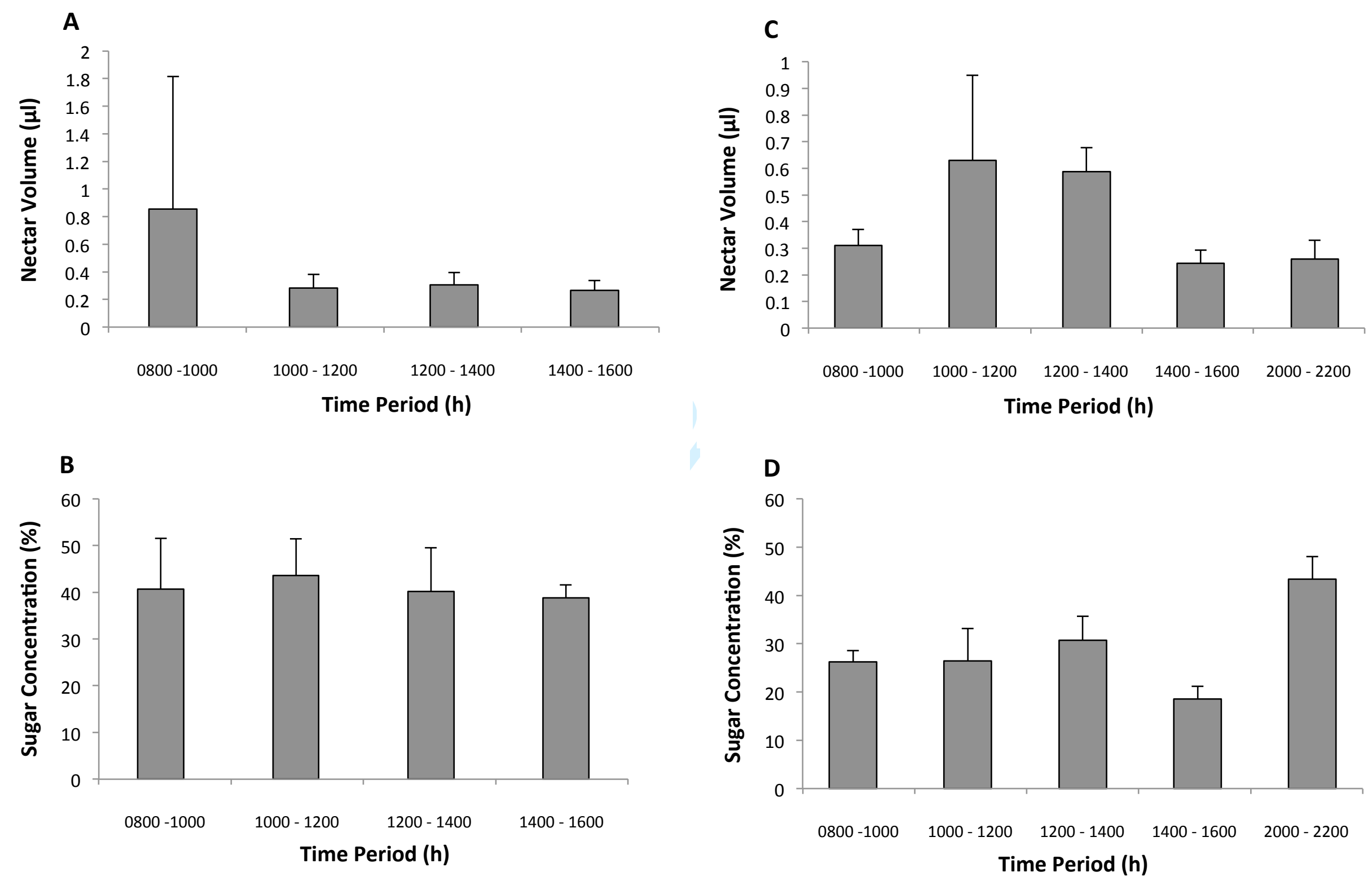

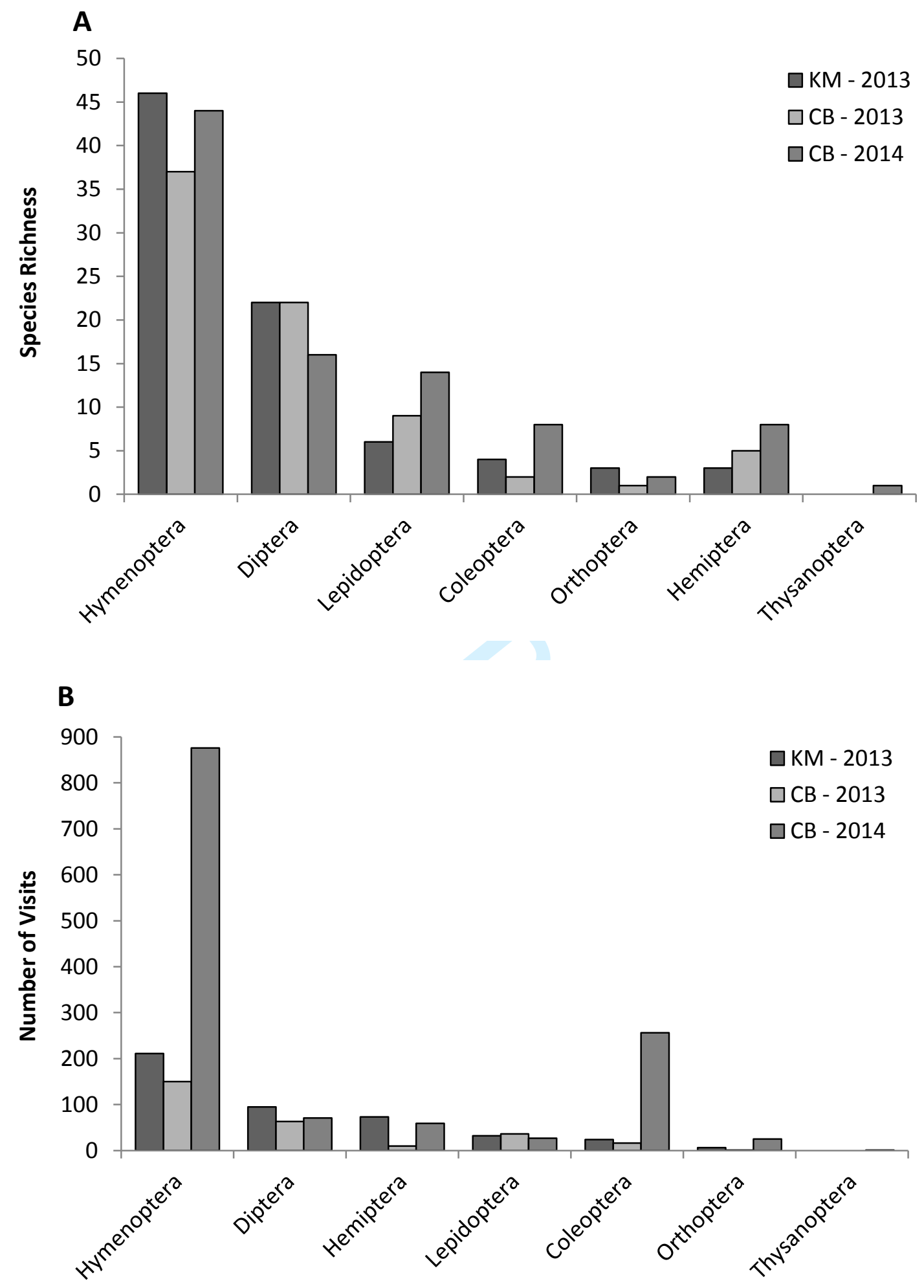

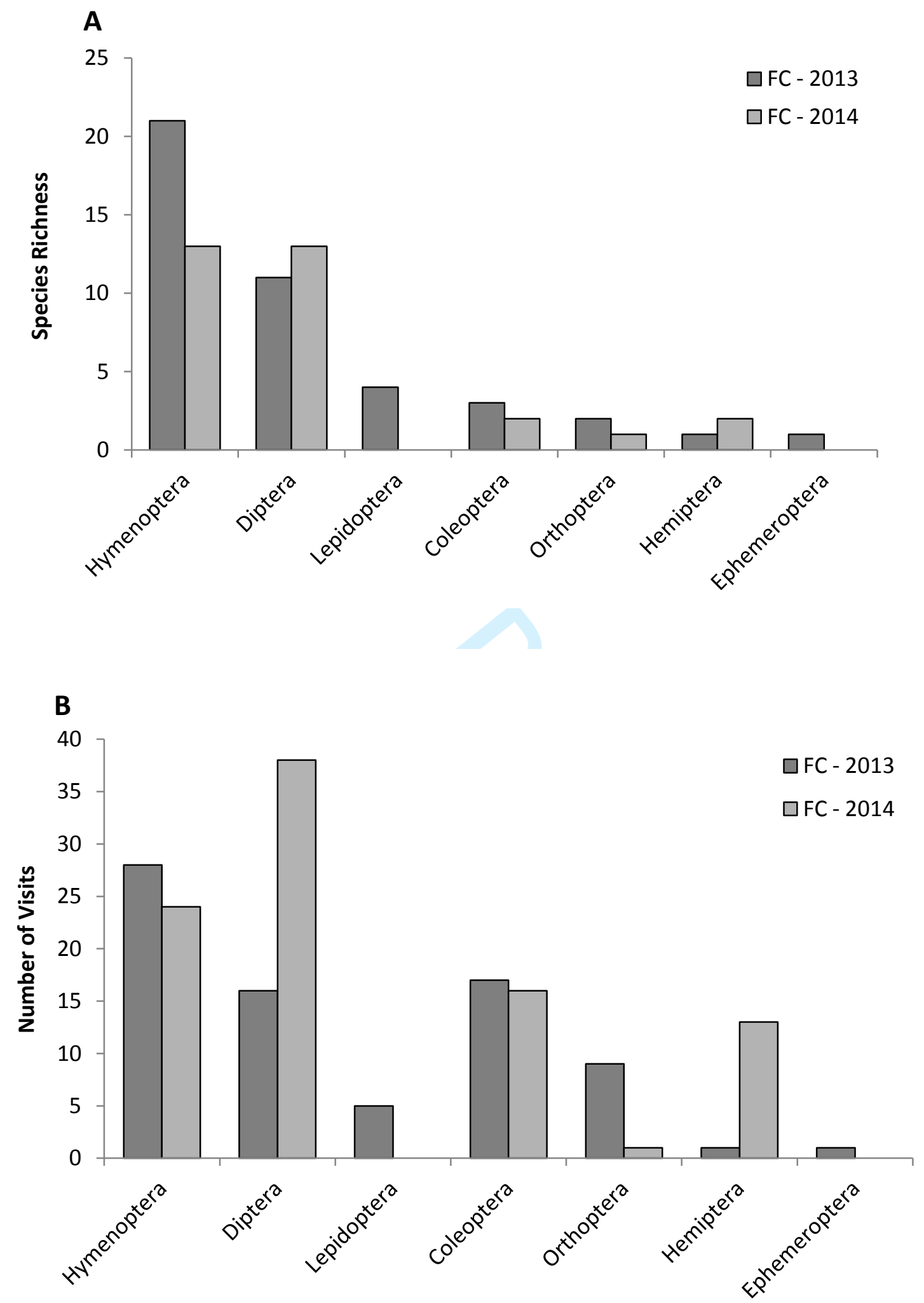


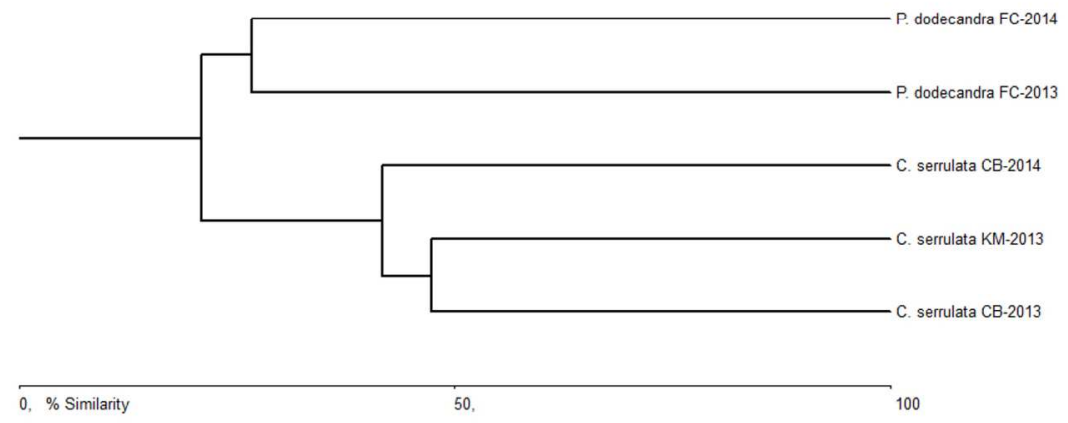

Jaccard similarity index dendrogram. $\mathrm{CB}=$ Casa Berardi, $\mathrm{FC}=$ Fish Creek, $\mathrm{KM}=$ Komati. $163 \times 69 \mathrm{~mm}(300 \times 300 \mathrm{DPI})$ 